\title{
Enhancing Mobile Learning Delivery through Exploration of the Learner Experience
}

\author{
Mohamed Ally, Ph.D. \\ Athabasca University \\ mohameda@athabascau.ca \\ Karen Stauffer, M.Sc. IS \\ Athabasca University \\ kstauff@athabascau.ca
}

\begin{abstract}
M-Learning research at the School of Computing and Information Systems (SCIS) at Athabasca University has been directed at improving mobile device access to distance learning materials through improved device detection, use of mobile device style sheets, and alternate files and graphics that are tailored to smaller screens. However, there is a greater significance placed in determining how learners perceive these enhancements to online learning. During this study, students were directed to access their regular online course materials using their mobile devices, then asked to complete a survey regarding their perception of this experience. This paper discusses the results from this study.
\end{abstract}

\section{Introduction}

As organizations look for flexible methods to deliver learning materials, they are looking at using mobile learning (M-Learning) to reach learners. Education is now being transformed by the use of wireless mobile technologies into M-Learning [9]. With the exponential growth of mobile devices used for Internet access throughout Canada and around the world, the School of Computing and Information Systems (SCIS) at Athabasca University positioned itself to meet the needs of students who want the flexibility to access their courses using mobile devices. At the start of the study, the SCIS already had the capability of delivering the course study guides and accompanying distance learning materials to a variety of mobile devices. However, there was still a great deal of work required to improve the device detection scheme and tailor the course materials for delivery to a mobile access. Once these tasks were accomplished, the research then was directed to ascertain from students using mobile devices how these enhancements were meeting their current needs and what improvements could be implemented in the near future for mobile access.

This research project was a continuation of the work started in an earlier project entitled "Preliminary Investigation into Mobile Learning Pedagogical Approaches and Technological Capabilities". Through this study, the School of Computing and Information Systems had confirmed the need for mobile delivery of course materials to our students and throughout the university. Athabasca University has been increasingly recognizing the requirement to deliver to the mobile learner. As a distance education organization, Athabasca University sees the importance for research and analysis of teaching and learning in a mobile environment. This need was identified and its importance emphasized in the Athabasca University Business Plan which states "Nurturing creative experimentation in networked research communities and mobilizing knowledge in a digital environment has the potential to transform the way we think about scholarly resources" [3]. This is consistent with the strategic direction of the University in the area of enhancing open access and recognizes that the workforce is increasingly more mobile [5]. The purpose of this study was to determine the devices being used by students, what they are accessing on the SCIS site using mobile devices, their experience with that access, and how useful they thought the mobile devices were to access course materials.

\section{Related Research}

As learning and training goes global, M-Learning is the first stage in the creation of a global provision of training on the wireless Internet [10]. It sets in place the first building block for the next generation of learning, which is the movement from distance 
learning (D-Learning) and electronic learning (ELearning) to mobile learning (M-Learning). However, M-Learning happens in the context in which it is needed and relevant and is situated within the active cognitive processes of individuals and groups of learners. As a result, learning is more relevant and effective with M-Learning [7]. Ring (2001) conducted a study to determine the effectiveness of a course delivered by wireless phone technology. Results indicated that $93 \%$ of students having wireless access reported that the technology made the course more convenient and they could work from anywhere. Students also reported that they were able to access courses while commuting. The wireless technology gave freedom to access the course from anywhere and students were able to get an overall feel for the content in the course. [12]

In a prior study done by Ally et al. (2005), the researchers explored the potential of mobile learning with the development of technology used in the pedagogical approaches to learning with mobile devices, which resulted in the determination that further research was required for advancement of the delivery methods [1]. One outcome determined was the need to resolve and test more robust methods of device detection and stylesheet delivery. Another was to review the course materials and determine which were not suitable for mobile delivery, and if so, what methods of adaptation could be offered.

The research of McGreal, R. et al (2005) "Implementing Mobile Environments using Learning Objects: The Athabasca University Digital Reading Room" identified in its report some of the technical difficulties in delivering to mobile devices. This project compared two different operating systems and their browsers, the Pocket PC and the Palm Pilot and identified several problems in delivering a generic style sheet to these two different systems including inconsistency in display of the content [11].

The SCIS course materials are developed in XML format using the IMS Learning Design specification. As a result, not only is the content separated from the presentation, it also identifies specific activities and learning objects within each unit of learning. This allows the opportunity to display the content in many different formats, in a wide range of layouts, and on a variety of devices. Device detection is done at the presentation level, and depending on the device detected, the stylesheet is selected that best matches the device [14].

At the beginning of the study there were severe limitations in the device detection method used. It involved a simple device detection JSP page as demonstrated below:
String user_agent = request.getHeader("user-agent"); if ((user_agent.equals..... mobile=true;

This code then required a set of referenced User Agent strings.

The problem was that it did not provide a robust method of device detection as new user agents appear on the mobile device market on an almost daily basis. One alternative that could be employed to improve on this method of delivery involves the Device Database API [8]. The scheme that was finally implemented was by detection of screen size. As described by Bowman (2004), the solution was to use JavaScript to detect a browser width equal to or greater than 800 pixels, which determines that the stylesheet is be delivered to a desktop browser. Otherwise, it is assumed that a smaller screen is being used and a stylesheet specific to a mobile device is delivered. This is an inverse solution to the problem, but it resolves the issue that many mobile devices do not recognize JavaScript [6].

Following the recommendations of the W3C Mobile Best Practices Document regarding presentation issues, the content for mobile devices needed to be arranged to best suit the size of the screen, the input devices, the bandwidth and cost, and the goals of the user [15]. During this study, all of the course materials used in the SCIS study guides were identified and tested on the mobile devices. Not only was the stylesheet adjusted for the mobile screen, but various multimedia files were tested and alternate methodologies for materials that mobile devices are not capable of viewing were implemented.

Also, under W3C Best Practices, since mobile browsers show a variety of characteristics, the testing should be carried out on as wide a range of devices as is practical [15]. The variety of devices used by students included iPaq devices, PalmOne Treos and Tungstens, Blackberries, Dell Axims, Pantech 3200s, Motorola Razors, Samsubgs, UT Starcoms, a Toshiba Pocket PC e330, and even a PSP (Portable Sony Playstation). The researchers used Palm Treos, a Samsung, a Dell Axim, and an iPAQ device. There was a complete range of connection plans including WiFi, phone plans, and desktop synchronization used by both students and researchers.

\section{Methodology}

The final (and most important) aspect of this research project was to explore the students' perception of these offerings and determine if the improvements to mobile delivery are meeting the needs of students using mobile devices. The target group was comprised 
of about 400 students taking a variety of online computer science courses. These students were selected because they all use online course materials for their studies and were currently active in the courses at the time of the study. The option to access their course materials using any mobile device was made available along with a request to complete the survey form. This was completely optional to the courses and it was hoped that at least $10 \%$ of these student would respond. At the end of the study, a total of 27 students had completed the survey. A check of the web server access logs shows that there were approximately 100 hits a day on the mobile devicespecific files.

The purpose of the survey was to determine the devices being used by students, what they are accessing on the SCIS site using mobile devices, their experience with that access, and how useful they thought using mobile devices to access course materials was.

In a research study conducted by ASTD and The MASIE Center ("If We Build It, Will They Come?"), the conclusion was drawn that while technologies can increase the efficiency and convenience of delivering courses to students, the assumption cannot be made that there will be satisfaction or acceptance of the technology on the students' side [2]. Robertson (2007) determined that even though mobile technologies are now extremely popular, the assumption that this would lead to a preference for their use with online learning has not yet been well-tested [13].

For the purpose of this study, mobile devices were not provided to students. One of the objectives of the research was to determine some of the types of devices that students currently own and use. The specific research design was one of experimentation using the sampling model. An assumption was made that the sample selected would be representative of the SCIS student body and it is expected the results could be generalized to the rest of the SCIS student body.

\section{Results}

The initial questions of the survey involved the type of device, their connection plans, the pages accessed, the typical number of times the students used their mobile devices to browse the Internet, and a description of any problems encountered accessing the SCIS course materials. The devices and connection plans were already briefly summarized. There were no critical errors in access. While some students needed to make some minor adjustments to their settings, all students were able to access the SCIS course materials web pages using their mobile devices.
The remaining questions of the survey are examined in more detail below:

\section{Statement 1: It is very useful having access to course materials from a mobile device.}

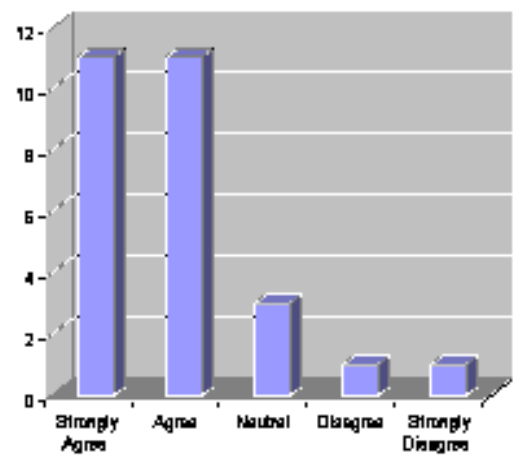

\section{Figure 1. Response to statement 1}

The majority of students either strongly agree or agree that it is useful to be able to access course materials with mobile devices. Some comments provided by students were:

- "Ability to use anywhere."

- "On the spot where it's needed"

- "The screen on the BB is very readable. I managed to finish reading an entire section while waiting for a meeting to start yesterday. This left me with a feeling of accomplishment and calm while the others were getting frustrated with the tardiness of the late comers."

- "The layout was fantastic \& easy to follow."

- "I actually really liked reading the course on the phone. If I didn't do this exercise I don't think I would have attempted it on my own."

Statement 2: Using a mobile device to access course materials increases convenience and flexibility in taking courses by distance learning.

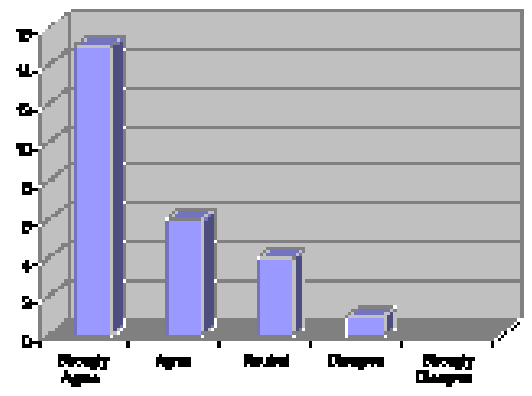

Figure 2. Response to Statement 2 
The majority of students said that they strongly agree that the use of mobile devices provides convenience and flexibility in taking courses by distance learning. Some comments provided by students to reinforce this outcome include:

- "Through this medium I am able to take the course anywhere I want in a small conveniently packaged mobile device."

- "I wouldn't use this method but probably many younger people would find it useful."

- "Yes, a mobile device does do that, but at the same time quality seems to be sacrificed."

- "There are many times in our busy lives where we could use our waiting time more constructively."

Statement 3: I would ideally like the following scenario for taking online courses:

\section{Table 1. Response to Statement 3}

\begin{tabular}{|c|c|}
\hline $\begin{array}{c}\text { Scenario } \\
\text { Preferred } \\
\end{array}$ & $\begin{array}{c}\text { Number } \\
\text { Responded }\end{array}$ \\
\hline $\begin{array}{l}\text { Mostly using a } \\
\text { desktop or laptop } \\
\text { computer with } \\
\text { some use of a } \\
\text { mobile device }\end{array}$ & 20 \\
\hline $\begin{array}{l}\text { Using a desktop } \\
\text { or laptop } \\
\text { computer } \\
\text { exclusively }\end{array}$ & 4 \\
\hline $\begin{array}{l}\text { Mostly using a } \\
\text { mobile device } \\
\text { with some use of } \\
\text { desktop or laptop } \\
\text { computer }\end{array}$ & 2 \\
\hline $\begin{array}{l}\text { Using a mobile } \\
\text { device } \\
\text { exclusively }\end{array}$ & 0 \\
\hline
\end{tabular}

Statement 4: Besides the course study guides, I would like to see any of the following available for access by mobile delivery

\section{Table 2. Response to Statement 4}

\begin{tabular}{l|l} 
Access Preferred & $\begin{array}{c}\text { Number } \\
\text { Responded }\end{array}$ \\
\hline $\begin{array}{l}\text { Access to Online } \\
\text { Assignments }\end{array}$ & 17 \\
\hline $\begin{array}{l}\text { Login to courses and } \\
\text { study materials }\end{array}$ & 15 \\
\hline
\end{tabular}

\begin{tabular}{l|l} 
Peer-to-peer interaction & 12
\end{tabular}

\begin{tabular}{l|l}
\hline Course Forums & 12 \\
\hline Access to Quizzes & 12 \\
\hline Access to Helpdesk & 11 \\
\hline $\begin{array}{l}\text { Group interaction sites } \\
\text { (such as facebook.com) }\end{array}$ & 8
\end{tabular}

Other comments from the responders:

- "Thanks for opening my eyes to this possibility - I'm going to enjoy my secret productive weapon for those dead times in my day. My compliments to the excellent formatting job you have done on the course notes. "

- "I think it is a good idea that you are beginning to get with the new age and letting us students access the courses through our mobile devices"،

- "Some cannot afford the rate packages that are on mobile web browsers."

- "Still doesn't replace a laptop in my opinion but useful when it's not available. Great for sitting at Starbucks or airport!"

\section{Discussion}

As was expected by the researchers, the majority of students responded that they either agreed or strongly agreed that the use of the mobile device to access the course materials was useful and provided both flexibility and convenience. Most users would mainly use a desktop for their courses though, with occasional use of the mobile device. This was also reflected in the comments as the size of the screen, the difficulty in typing, the cost of web access, and the quality of the screen output are all impediments to constant use of a mobile device. However, the convenience of being able to take the course work along to wherever the students were, and whenever they were able to access their course work was of significant value, as noted in both the comments and the statement numbers. The smaller number of users who did not find the mobile device useful at all identified the same impediments to mobile device usage for course materials access.

One demographic to note in this study is that while the age of the students was not determined in this survey, it may be a factor in the outcome. Athabasca University lists the average of average age of their students as 29 years of age. [4]. Based on this demographic, an assumption could be drawn that the average AU student does not interact with a mobile device as often as the typically younger student in a traditional university. This may account for the lower 
numbers than expected for the peer-to-peer interaction and the group interaction desirability.

\section{Conclusion}

This research study confirmed among the SCIS students, an interest in using mobile devices to access course materials. The improvements to the SCIS course delivery methods including device detection and style sheet modifications were well-regarded by the learners, and overall most learners agreed with the usefulness and convenience of using mobile devices to access these. However, while M-Learning is apparently gaining in popularity, this study is an indication that developers should take an eclectic approach when developing distance education courses. At this point in time and based on the outcome of this study, the general consensus is that M-Learning does not significantly replace the use of the desktop computers in access to course materials for distance learning at Athabasca University's School of Computing and Information Systems. It does, on the other hand, provide an enhancement to distance learning through increasing flexibility in course material access. As well, the study did introduce a few of the learners to the concept of using mobile devices for online learning. Research should continue to determine to what degree future (and likely increasingly sophisticated) mobile users' interest in M-Learning has developed.

\section{References}

[1] Ally, M., Lin, F., McGreal, R., Woo, B., Li, Q. “An intelligent agent for adapting and delivering electronic course materials to mobile learners." Retrieved October 10, 2006 from http://hdl.handle.net/2149/216

[2] ASTD and The MASIE Center. (2001). E-Learning: "If We Build It, Will They Come?” (Executive Summary). Retrieved September 10, 2007 from http://www.masie.com/masie/researchreports/ASTD_Exec_ Summ.pdf

[3] Athabasca University 2006-2007 Business Plan. Retrieved October 10,2006 from

http://www.athabascau.ca/main/bizplans/06_2010_Plan.pdf

[4] Athabasca University. "Facts and Statistics". Retrieved September 172007 from

http://www.athabascau.ca/newsroom/press/facts.php

[5] Athabasca University Strategic University Plan 20062011 (Highlights). Retrieved October 10,2006 from http://www.athabascau.ca/sup/SUP_highlights_09_08.pdf
[6] Bowman, Douglas. (2004). "Targeting Small Screens". Retrieved January, 2007 from http://www.stopdesign.com/log/2004/12/16/smallscreens.html

[7] Brown, J. S., Collins, A., \& Duguid, P. (1989). "Situated cognition and the culture of learning." Educational Researcher, 32-42.

[8] Fling, B. “The Mobile Device Detection Problem." Retrieved October 10, 2006

http://mobiledesign.org/articles/the_mobile_device_detectio n_problem.php

[9] Kassop, M. (2003, May/June). "Ten ways online education matches, or surpasses, face-to-face learning" [Electronic Version]. The Technology Source, Retrieved July 3, 2003, from

http://ts.mivu.org/default.asp?show=article \&id=1059

[10] Keegan, D. (2002, November). The future of learning: ZIFF papiere 119: From eLearning to mLearning, Retrieved http://www.fernuni-hagen.de/ZIFF/ZIFF_PAP_119.pdf

[11] McGreal, R., Cheung, B., Tin, T., Schafer, S. (2005, June). "Implementing Mobile Environments using Learning Objects: The Athabasca University Digital Reading Room." Retrieved October 10,2006 from http://hdl.handle.net/2149/214

[12] Ring, G. (2001, June). Case study: Combining Web and WAP to deliver e-Learning. Learning Circuits, ASTD Online Magazine, Retrieved September 28, 2007, from

http://www.learningcircuits.org/2001/jun2001/ring.html

[13] Robertson, Ian. (2007). "Technology-based learning: Problematising VET students' preferences and readiness". Refereed Paper Presented at 2007 AVETRA Conference, 1113 April 2007, Victoria University. Retrieved September 10, 2007 from

http://robboian.googlepages.com/AVETRA2007_IR.pdf

[14] Stauffer, K. L. (2005). XML, IMS Learning Design, and Learning Object Development for Web Course Delivery.

MSc IS Thesis, Athabasca University, 2005.

[15] W3C. "Mobile Web Best Practices 1.0." Retrieved October 10, 2006 from http://www.w3.org/TR/mobile-bp/ 